\title{
AC 2012-4969: IMPROVING CONFIDENCE LEVEL AND PERFORMANCE OF FIRST GENERATION AND FEMALE STUDENTS USING METACOG- NITION STRATEGIES
}

\section{Dr. Quamrul H. Mazumder, University of Michigan, Flint}

Quamrul Mazumder is a professor of mechanical engineering at University of Michigan, Flint. His research interests includes computational fluid dynamics, metacognition approaches of learning, active and experiential learning, renewable energy, and global engineering education. His teaching areas are fluid mechanics, renewable energy, introduction to engineering, and senior design. 


\title{
Improving Confidence Level and Performance of First Generation and Female Students Utilizing Metacognition Strategies
}

\begin{abstract}
The number of first generation students in engineering programs has been growing during the past few years. However, the number of female students enrolled in engineering and technology programs has been stagnant despite the fact that overall female enrollment at universities has increased. In addition, some first generation college students have entered school with cultural and socio-economic backgrounds that may hinder their success. Therefore, these students are more likely to possess a lower level of confidence, which may impose a barrier to their success. The objective of this study is to investigate the impact of how metacognition strategies can be utilized to improve the confidence level of students, which may affect academic performance and professional career choices.

This study utilized quantitative analysis by measuring confidence levels with in-class surveys before and after lectures. Exam scores were recorded to measure the impact of the variables using non-parametric descriptive statistics, repeated measures correlation, and paired sample ttests. The results demonstrated that all three groups (first generation students, female students, and students from different ethnic backgrounds) improved their confidence level and academic performance through metacognition strategies. The utilization of metacognition strategies had a positive impact on first generation students, female students, and minority students with disadvantaged ethnic backgrounds since metacognition increased the students' motivation and promoted better study habits. Consequently, these findings can help understand how metacognition strategies can be implemented to improve the performance, retention rate, and graduation rate of such students in engineering programs.
\end{abstract}

\section{Introduction}

The confidence level one has while performing tasks can significantly affect one's choice of career, academic major, and whether or not to pursue higher education and professionalism. This fact is especially evident for first generation college students, female students, and students from underprivileged ethnic backgrounds. The purpose of this study is to investigate the impact of metacognition strategies on the confidence level of such engineering students. The following research questions were used as a guiding principle in this study:

- Do first generation college students have different confidence levels than non-first generation students?

- Are the confidence levels of female students different from those of male students when performing a problem-solving task?

- Do students from certain ethnic backgrounds demonstrate higher confidence levels in problem solving activities? 
To test the theory that higher achieving students employ metacognition strategies, a nonequivalent (pre/post-test) quasi-experimental design was created. The independent variable in the study was defined as the level of confidence of a student, which was measured by pre-lecture confidence ratings and expected exam scores. The dependent variable was defined as academic achievement, which was measured by the grades a student received on quizzes and exams. The data was collected from fifty-four engineering students over a period of three consecutive years. Different methods were utilized to assess confidence levels including self-assessments before and after lectures and exams. For the pre-tests, students were required to assess their own level of understanding of the material. Afterward, for the post-tests, students were required to reflect on the depth of their own knowledge concerning the topic, which is the basis of metacognition.

\section{Literature Review}

Cognitive self-appraisal is "judgments about one's personal cognitive abilities, task factors that influence cognitive difficulty or cognitive strategies that may facilitate or impede performance" ${ }^{1}$. In metacognition, when analyzing personal confidence judgments, one must introspect. Confidence judgments are the most commonly used method for determining whether an individual's belief that the information recalled from memory is accurate ${ }^{2}$. Confidence judgments consist of both the cognitive process of confidence assessment and the subjective feelings of confidence.

To effectively learn, one must possess a clear understanding of metacognition ${ }^{3}$, which is pivotal to success. To employ metacognitive strategies, the learner must be aware of how he/she learns and possess the ability to control the learning process. An important characteristic of a successful student is the capability to assess and regulate his/her own learning behavior while striving for a deeper level of understanding. In order to demonstrate higher levels of cognitive sophistication (CS), confidence in a learner's knowledge must be achieved through deep learning rather than surface learning. One of the greatest barriers to learning is a student's inability to apply his/her knowledge when required to solve problems ${ }^{4}$. This is due to the student's lack of training in critical thinking at a high cognitive level. In order to employ metacognitive strategies in the classroom, teachers must implement the following strategies into their curriculum: (1) furthering general awareness of the significance of metacognition, (2) enhancing knowledge of cognition, (3) enhancing control of cognition, and (4) encouraging environments that advance metacognitive awareness. Activities and assignments should be designed in such a way that the students are actively thinking and engaging the concepts and principles of the course. Wellorganized teaching or the use of developmental strategies may offset large variances in IQ ${ }^{6}$.

One of the most important goals of an instructor is to involve students in the learning process, so students assume responsibility for their own learning. Classroom instruction should ensure students comprehend both the learning objectives and the outcomes of the material ${ }^{7}$. This type of teaching encourages the development of confidence among students. Therefore, lessons must be planned in such a way that students are able to think about the content and actively engage themselves in the learning process. An example of this is direct instruction, which features "systematic sequencing of lessons, including the use of review, presentation of new content and skills, guided student practice, the use of feedback, correctives, and independent 
student practice" ${ }^{7}$. Initial internalization of a new concept is essential for learning material. Moreover, immediately applying a freshly learned concept to a new problem demonstrates the value of deep learning utilizing metacognitive strategies.

Lawanto ${ }^{8}$ reported several studies conducted in the area of metacognition to improve academic performance of students. Metacognition is often referred to as the ability to think about thinking, and it plays an important role in learning ${ }^{9-13}$. Investigators have reported a positive correlation between metacognition and performance and have concluded metacognition is a fundamental tool that enables learners to control their own cognition, emotions, and motivation.

According to one theory, first generation college students have a higher intrinsic motivation to graduate since they are the first of their family to attend college. This hypothesis will be tested to prove or disprove its validity. For instance, there may be unforeseen factors as well such as family support and a higher confidence level, which can contribute to overall academic performance. Many female students experience gender segregation in the maledominated engineering profession throughout their education and professional careers. This separation of the sexes begins to emerge early in one's professional education, and it continues to plague women throughout their careers. Due to this sexism, women engineers can doubt their own abilities, competencies, anticipated roles, and personal fit ${ }^{14,15}$. Therefore, the confidence level of female students is significantly drained. $\mathrm{Cecz}^{16}$ reported the difference in the retention of men and women in the male-dominated engineering profession emerges from seemingly voluntary individual decisions to stay or leave.

For ethnic minorities, it is not uncommon to bring their "cultural medium," which is defined as "behaviors they have gained through interactions in various social situations" into education". Thus, "learning and doing are more than a cognitive activity as ways of knowing and doing are unique to each group, and can be called its specific culture" ${ }^{\prime 18}$. This sense of belonging to a specific culture usually adds to the confidence level of minority students. However, when entering the field of engineering, minority students must overcome cultural differences, which may have an adverse impact on their self-esteem and confidence levels.

\section{Method and Instrument}

Fifty-four freshmen engineering students consisting of thirty-nine males and fifteen females participated in the study. The ethnicities of the students included two Latinos/Hispanics, seven Asians, ten African-Americans, and thirty-five Caucasians. In addition, seven students were first generation students and forty-seven were non-first generation students.

The questionnaires (pre/post lecture and pre/post test) was designed based on previous research results and experience of the author in the area of metacognition. The questions were specifically designed to measure aptitude, motivation, and the ability to self-regulate. The aptitude portion investigated "students' perception of their learning strategies, abilities, and the thought processes related to identifying, acquiring, and constructing meaning for important new information, ideas, and procedures"19. The motivation component measured "students" perceptions of their receptivity to learning new information, their attitudes \& interests in college, their diligence, their self-discipline, their willingness to exert the effort necessary to successfully 
complete academic requirements, and the degree to which they worry about their academic performance". The self-regulation component examined students' perceptions of how well they manage the learning process through using their time effectively, focusing their attention \& maintaining their concentration over time, checking to see if they have met learning demands (for a class, assignment, or test), and using study supports (review sessions, tutors, or special features of a textbook $)^{19}$. The responses were measured on a Likert scale from 0-10 with zero being the lowest, or in total disagreement, and ten being the highest, or in total agreement.

\section{Statistical Analysis Results}

A paired sample t-test was conducted comparing the mean test scores to confidence levels for all three categories: (1) first generation students versus non-first generation students, (2) male students versus female students, and (3) Latino/Asian/African-American/Caucasian.

Paired sample t-statistics results of first generation students versus non-first generation students are reported in Table 1 below. A comparison of first generation students to non-first generation students confirmed the first generation students not only possessed higher confidence levels but also performed better on the midterm exam. Whereas the mean midterm score of first generation students was $(M=37.14)$ and the confidence level was $(M=8.029)$, non-first generation students earned lower mean scores on the midterm exam and confidence level, $(M=34.89)$ and $(M=$ 7.562) respectively.

Table 1: Comparison of First Generation Vs. Non-First Generation (Regular) Students

\begin{tabular}{|c|c|c|c|c|c|c|}
\hline \multicolumn{3}{|c|}{ Generation } & Mean & $\mathrm{N}$ & $\begin{array}{c}\text { Std. } \\
\text { Deviation }\end{array}$ & $\begin{array}{c}\text { Std. Error } \\
\text { Mean }\end{array}$ \\
\hline \multirow{6}{*}{$\begin{array}{l}1 \\
\text { (First } \\
\text { Gen.) }\end{array}$} & Pair 1 & Actual Grade Q1/20 & 13.29 & 7 & 2.563 & .969 \\
\hline & & Conf1/Q1 & 7.43 & 7 & 1.813 & .685 \\
\hline & Pair 2 & MidTerm Grade/50 & 37.14 & 7 & 10.746 & 4.062 \\
\hline & & Conf1/MT & 8.029 & 7 & 1.6101 & .6086 \\
\hline & Pair 3 & $\begin{array}{l}\text { Actual Grade } \\
\text { Q2/20 }\end{array}$ & 11.71 & 7 & 2.059 & .778 \\
\hline & & Conf1/Q2 & 6.500 & 7 & .8660 & .3273 \\
\hline \multirow{6}{*}{$\begin{array}{l}2 \\
\text { (Non } \\
\text { First } \\
\text { Gen) }\end{array}$} & Pair 1 & Actual Grade Q1/20 & 13.40 & 47 & 3.132 & .457 \\
\hline & & Conf1/Q1 & 7.62 & 47 & 1.636 & .239 \\
\hline & Pair 2 & MidTerm Grade/50 & 34.89 & 47 & 12.269 & 1.790 \\
\hline & & Conf1/MT & 7.562 & 47 & 2.0674 & .3016 \\
\hline & Pair 3 & $\begin{array}{l}\text { Actual Grade } \\
\text { Q2/20 }\end{array}$ & 13.02 & 47 & 3.602 & .525 \\
\hline & & Conf1/Q2 & 7.255 & 47 & 1.8936 & .2762 \\
\hline
\end{tabular}

The results for the second category, male students versus female students, confirmed female confidence was initially lower than that of males. For instance, the confidence level of female students was lower than that of male students on test one and the midterm exam $(M=6.87 \&$ 
6.613 versus $7.87 \& 8.010$ respectively). However, the mean test score on the midterm exam for males was lower than that for females ( $M=34.49$ versus 37.00 respectively). In addition, female students had a higher score on test two than male students ( $M=14.00$ versus 12.41 respectively). Interestingly, by the end of the semester, the grades and confidence level of female students had surpassed those of their male counterparts. For example, on test one, male students had a slightly higher test score $(M=13.49$ versus 13.13) and confidence level ( $M=7.87$ versus 6.87$)$. However, on test two the males had a slightly lower test score $(M=12.41$ versus 14.00$)$ and confidence level $(M=7.000$ versus 7.567). In addition, male students possessed a higher confidence level than females before the midterm exam ( $M=8.010$ versus 6.613 respectively). Despite their lower confidence level, the female students outperformed the male students $(M=37.00$ versus 34.49 respectively).

Table 2: Paired Sample Statistics of Male Students Versus Female Students

\begin{tabular}{|lll|c|c|c|c|}
\hline & Gender M=1, F=2 & Mean & $\mathrm{N}$ & $\begin{array}{c}\text { Std. } \\
\text { Deviation }\end{array}$ & $\begin{array}{c}\text { Std. Error } \\
\text { Mean }\end{array}$ \\
\hline 1 & Pair & Actual Grade Q1/20 & 13.49 & 39 & 2.990 & .479 \\
Male & 1 & Conf1/Q1 & 7.87 & 39 & 1.418 & .227 \\
& Pair & Mid-Term Grade/50 & 34.49 & 39 & 12.074 & 1.933 \\
& 2 & Conf1/MT & 8.010 & 39 & 1.4832 & .2375 \\
& Pair & Actual Grade & 12.41 & 39 & 3.193 & .511 \\
& 3 & Q2/20 & & & & \\
& & Conf1/Q2 & 7.000 & 39 & 1.6859 & .2700 \\
\hline 2 & Pair & Actual Grade Q1/20 & 13.13 & 15 & 3.270 & .844 \\
Female & 1 & Conf1/Q1 & 6.87 & 15 & 1.995 & .515 \\
& Pair & Mid-Term Grade/50 & 37.00 & 15 & 12.071 & 3.117 \\
& 2 & Conf1/MT & 6.613 & 15 & 2.7872 & .7196 \\
& Pair & Actual Grade & 14.00 & 15 & 3.946 & 1.019 \\
& Q2/20 & & & & \\
& Conf1/Q2 & 7.567 & 15 & 2.0948 & .5409 \\
\hline
\end{tabular}

A paired sample t-test was conducted to compare the mean midterm exam score and confidence level of male students to female students. The results are reported in Table 3 below. Although male confidence remained higher than females, the females outperformed the males on all levels of exams in this engineering course. 
Table 3: Paired Samples Test ${ }^{\mathrm{a}}$ (t-Statistics) of Male Students Versus Female Students

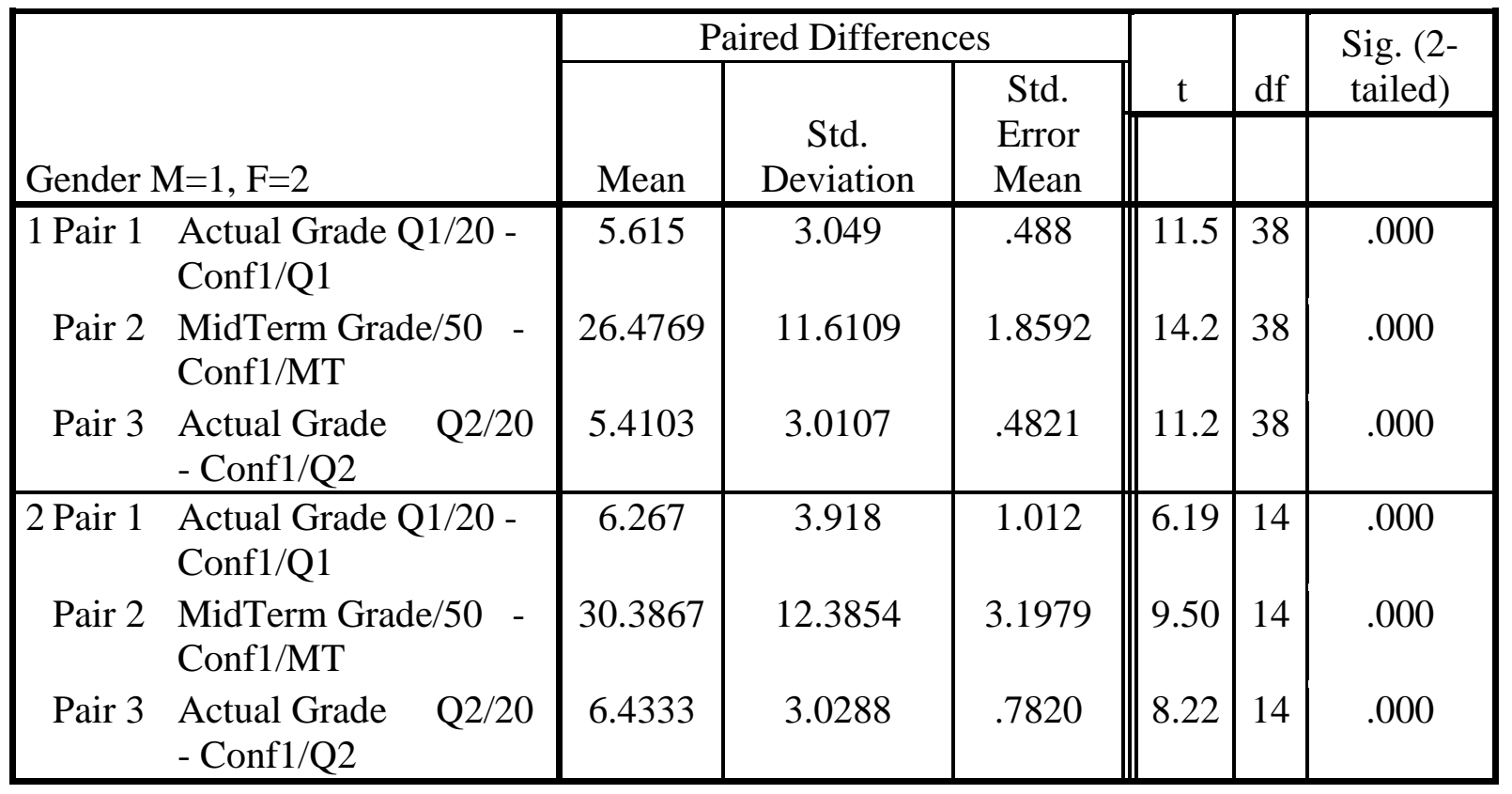

The results for the third category are presented in Table 4 below. The results of the four aforementioned ethnicities were compared to confirm whether one group performed better than others. When the mean midterm exam scores were compared, it was discovered Asian students scored significantly higher $(M=44.29)$ than Latino students ( $M=27.50)$, African American students $(M=33.89)$, and Caucasian students $(M=34.17)$. In addition, the mean confidence level of Asian students was the highest of the ethnicities. 
Table 4: Paired Sample Statistics of Different Ethnicities

\begin{tabular}{|c|c|c|c|c|c|c|}
\hline \multicolumn{3}{|c|}{ Ethnicity } & Mean & $\mathrm{N}$ & Std. Deviation & Std. Error Mean \\
\hline \multirow{7}{*}{$\begin{array}{c}1 \\
\text { Latino }\end{array}$} & \multicolumn{2}{|c|}{ Pair Actual Grade Q1/20 } & 12.50 & 2 & 3.536 & 2.500 \\
\hline & 1 & Conf1/Q & 8.00 & 2 & .000 & .000 \\
\hline & \multirow{3}{*}{$\begin{array}{c}\text { Pair } \\
2\end{array}$} & Mid-Term & 27.50 & 2 & 24.749 & 17.500 \\
\hline & & Grade/50 & & & & \\
\hline & & Conf1/MT & 7.500 & 2 & .7071 & .5000 \\
\hline & \multicolumn{2}{|c|}{ Pair Actual Grade Q2/20 } & 12.00 & 2 & 2.828 & 2.000 \\
\hline & 3 & Conf1/Q2 & 6.000 & 2 & 1.4142 & 1.0000 \\
\hline \multirow{7}{*}{$\begin{array}{c}2 \\
\text { Asian }\end{array}$} & \multicolumn{2}{|c|}{ Pair Actual Grade Q1/20 } & 13.86 & 7 & 3.671 & 1.388 \\
\hline & 1 & Conf $1 / \mathrm{Q} !$ & 6.86 & 7 & 2.268 & .857 \\
\hline & \multirow{3}{*}{$\begin{array}{c}\text { Pair } \\
2\end{array}$} & Mid-Term & 44.29 & 7 & 8.864 & 3.350 \\
\hline & & Grade/50 & & & & \\
\hline & & Conf1/MT & 7.857 & 7 & 3.3877 & 1.2804 \\
\hline & \multicolumn{2}{|c|}{ Pair Actual Grade Q2/20 } & 17.43 & 7 & 2.760 & 1.043 \\
\hline & 3 & Conf1/Q2 & 8.286 & 7 & 3.3022 & 1.2481 \\
\hline \multirow{7}{*}{$\begin{array}{c}3 \\
\text { African }\end{array}$} & \multicolumn{2}{|c|}{ Pair Actual Grade Q1/20 } & 13.44 & 9 & 1.667 & .556 \\
\hline & 1 & Conf1/Q! & 7.78 & 9 & 1.716 & .572 \\
\hline & \multirow{3}{*}{$\begin{array}{c}\text { Pair } \\
2\end{array}$} & Mid-Term & 33.89 & 9 & 13.411 & 4.470 \\
\hline & & Grade/50 & & & & \\
\hline & & Conf1/MT & 7.156 & 9 & 2.0464 & .6821 \\
\hline & \multicolumn{2}{|c|}{ Pair Actual Grade Q2/20 } & 12.00 & 10 & 3.127 & .989 \\
\hline & 3 & Conf1/Q2 & 7.750 & 10 & 1.0865 & .3436 \\
\hline \multirow{7}{*}{$\begin{array}{c}4 \\
\text { Caucacian }\end{array}$} & \multicolumn{2}{|c|}{ Pair Actual Grade Q1/20 } & 13.33 & 36 & 3.260 & .543 \\
\hline & & Conf $1 / \mathrm{Q} !$ & 7.67 & 36 & 1.549 & .258 \\
\hline & \multirow{3}{*}{$\begin{array}{c}\text { Pair } \\
2\end{array}$} & Mid-Term & 34.17 & 36 & 11.180 & 1.863 \\
\hline & & Grade/50 & & & & \\
\hline & & Conf1/MT & 7.700 & 36 & 1.7569 & .2928 \\
\hline & \multicolumn{2}{|c|}{ Pair Actual Grade Q2/20 } & 12.23 & 35 & 3.078 & .520 \\
\hline & 3 & Conf1/Q2 & 6.829 & 35 & 1.4948 & .2527 \\
\hline
\end{tabular}

\section{Summary and Conclusion}

Based upon previous studies on metacognition, it was hypothesized first generation students would have higher confidence levels than non-first generation students. The results did find significant differences in confidence levels at the midterm point of the semester. Arguably, after 
employing metacognitive strategies, these students performed better and had higher confidence levels than non-first generation students. The question remains, however, whether the performance and motivation of first generation students increased after employing metacognitive strategies or did the students simply develop better study habits? We believe the former to be the case; however, additional research needs to be conducted in this area to confirm our results.

The second hypothesis stated that female students have differences in confidence levels involving problem-solving activities when compared to male students. The results of our study found a significant difference between the confidence levels of females and those of their male counterparts. Studies have found that women have more difficulty adapting to the engineering culture due to lower confidence and esteem levels. Although it has been proven that females may excel academically, when it comes to making the transition into the workplace, they lack confidence and self-esteem in their abilities to integrate into the gender biased work environment. For example, "one woman engineer received a phone call asking for the engineer in charge. When she replied that she was the engineer in charge, they said no, I want to speak to the real engineer" 20 . There was another instance of a woman being fired from her job because the project engineer refused to work with a woman engineer ${ }^{20}$. Although women are making great strides in the field of engineering, the gender disparity gap still exists. This study focused on improving the confidence level of female engineering students through the use of metacognition strategies. Although the results were significant, further studies need to be conducted in this area of research.

Comparing students from different ethnic backgrounds to determine whether ethnic background has any effect on performance tested the third hypothesis. The analysis results revealed that Asian and Caucasian students outperformed all others in both the mid-term exams and quiz 2 as shown in Table 4. In the face of cultural disparities in the workplace, students from various ethnic backgrounds are faced with other factors as well. Such factors in include "discriminatory and cultural factors such as biased hiring and chilly climates. Such factors begin early in the professional education process and continue through one's career, and include individually held beliefs about one's abilities, competencies, anticipated roles and personal fit $^{14,15}$.

\section{Future Study:}

One concern of this study was the reliability of the responses in the questionnaire. Further research should investigate the reliability of the confidence level reported by students.

\section{Acknowledgement:}

This study was conducted under NSF grant 087139: Evaluating Online Metacognition Tools and Strategies for Their Use. The author would like to thank the University of MichiganFlint Office of Research for support in preparing the manuscript. 


\section{References}

[1] Paris, S. G., \& Winograd, P., (1990). Metacognition in academic learning and instruction. In B.F. Jones (Ed.), Dimensions of thinking and cognitive instruction. Mahwah, NJ: Erlbaum, 15-44.

[2] Chua E. F., Schacter, D. L., Rand-Giovannetti, E., Sperling, R. A., (2006). Understanding metamemory: neural correlates of the cognitive process and subjective level of confidence in recognition memory. NeuroImage, 29, $1150-1160$.

[3] Rowe, H., (1988). Metacognitive skills: Promises and problems, Australian Journal of Reading, 11(4), 227-237.

[4] Redding, R. E. (1990). Metacognitive instruction: Trainers teaching thinking skills, Performance Improvement Quarterly, 3(1), 27-41.

[5] Hartman, H.H., Sternberg, R.J., (1993). A broad BACEIS for improving thinking. Instructional Science 21, 401-425.

[6] Schraw, G., (1998). Promoting general metacognitive awareness. Instructional Science. 26, 113-125.

[7] Wang, M.C.,Haertel, G.D.,Walberg, H.J., (1993). What helps students learn? Educational Learning 51(4), 7479.

[8] Lawanto, O., (2010). Students' metacognition during an engineering design project. Performance Improvement Quarterly, 23 (2), 117-136.

[9] Chambred, P., Bonbin, D., Izaute, M., \& Marescaux, P.J., (2002). Metacognition triggered by social aspect of expertise. Metacognition Process, Function and Use, Norwell, MA: Kluwer, 153-168.

[10] Chan, L. K. S. \& Moore, P. J., (2006). Development of attributional beliefs and strategic knowledge in years 5 to 9: A longitudinal analysis. Educational Psychology, 26 (2), 161-185.

[11] Graves, D. H., (1983). Writing, teachers and children at work. Portsmouth, NH:Heinemann Educational Books. [12] Jonassen, D., Strobel, J., \& Lee, C.B., (2006). Everyday problem solving in engineering: Lessons for engineering educators. Journal of Engineering Education, 95 (2), 139-151.

[13] Ross, M. E., Green, S. B., Salisbury-Glennon, J. D., \& Tollefson, N., (2006). College students' study strategies as a function of testing: An investigation into metacognitive self-regulation. Innovative Higher Education, 30 (5), 361-375.

[14] Cech, E.A., (2007). Dilbert in Stilettos: the character of deterrents facing women in engineering, Gender and Engineering: Strategies and Possibilities, Frankfort, Germany: Peter Lang Press, 33-50.

[15] Xie, Y. \& Shauman, K. (2003). Women in Science. Cambridge, MA: Harvard University Press.

[16] Cech, E.A., Rubineau, B., Silbey, S., \& Seron, C., (2011). Professional role confidence and gendered persistence in engineering, American Sociological Review, 76 (5), 641-666.

[17] Correll, S.J., (2001). Gender and the career choice process: The role of biased self- assessment, American Journal of Sociology, 106, 1691-1730.

[18] Strickfaden, M., Heylighen, A., Rodgers, P., \& Neuckermans, H., (2005). The "culture medium" in design education. In P. Rodgers, L. Brodhurst \& D. Hepburn (Eds.), Crossing design boundaries. Leiden, The Netherlands: Taylor \& Francis/Balkema, 59-64. 
[19] Downing, K., Ning, F., \& Shin, K., (2011). Impact of problem-based learning on student experience and metacognitive development, Multicultural Education \& Technology Journal, 5 (1), 55-69.

[20] Dryburgh, H., (1999). Work Hard, Play Hard: Women and professionalization in engineering adapting to the culture, Gender \& Society, 13 (5), 664-682. 